\title{
PENGUASAAN KEMAHIRAN MEMBACA DAN MENULIS BAHASA MELAYU DALAM KALANGAN MURID BUKAN PENUTUR NATIF DI SEKOLAH JENIS KEBANGSAAN (SJK)
}

\author{
Nora'Azian Nahar \\ Jabatan Bahasa Melayu \\ Kulliyah Bahasa dan Pengurusan \\ Universiti Islam Antarabangsa Malaysia \\ noraazian@iium.edu.my
}

Manuscript received 22 April 2020

Manuscript accepted 8 June 2020

${ }^{*}$ Corresponding author

https://doi.org/10.33736/ils.2223.2020

\begin{abstract}
ABSTRAK
Ketidaklancaran kemahiran membaca dan kelemahan penguasaan kemahiran menulis dilihat sebagai punca kemerosotan pencapaian akademik belakangan ini di sekolah rendah. Kajian dijalankan untuk mengenal pasti tahap penguasaan membaca dan menulis dalam bahasa Melayu murid di Sekolah Rendah Jenis Kebangsaan (SJK). Seramai 414 orang sampel kajian dari lima buah sekolah SJK telah dipilih. Dua instrumen yang diguna pakai untuk mendapatkan data iaitu Ujian Profesiensi UPBM_SR dan Tahap Skor UPBM_SR. Data diproses menggunakan IBMSPSS Versi 23 dengan reka bentuk tinjauan keratan rentas. Dapatan kajian menunjukkan terdapat sebanyak $65.2 \%$ responden tidak menguasai kemahiran menulis dan 39.6\% tidak lancar membaca dalam bahasa Melayu. Pemahaman input kemahiran membaca dan menulis dilihat satu-satunya mekanisme yang dapat meningkatkan kecekapan linguistik asas. Peranan semua pihak perlu digembleng untuk melahirkan generasi yang kompeten menggunakan bahasa kebangsaan di Malaysia.
\end{abstract}

Kata Kunci: bahasa kedua; membaca dan menulis; murid bukan penutur natif; kecekapan 


\title{
The Mastery of Malay Reading and Writing Skills Among Students of Non- Native Speakers in National-Type School
}

\begin{abstract}
The lack of mastery in reading skills and writing skills are seen as the main cause of the declining of academic achievements in primary school these days. The study was conducted to identify the level of mastery of reading and writing skills in Malay language of students in Sekolah Rendah Jenis Kebangsaan (SJK). A total of 414 study samples from five SJK schools were selected. Two instruments used to obtain data were the UPBM_SR Proficiency Test and the UPBM_SR Score Level. Data were processed using IBMSPSS Version 23 with cross-sectional survey design. The findings show that $65.2 \%$ of respondents did not master the skills of writing and $39.6 \%$ did not know how to read fluently in Malay. Understanding the input of reading and writing skills is seen as the only mechanism that can improve basic linguistic proficiency. The role of all parties should be strengthened to foster a generation that is competent in using the national language of Malaysia
\end{abstract}

Keywords: second language, reading and writing skills, non-native learners, proficiency.

\section{Pendahuluan}

Proses menerima komunikasi dan menghasilkan bahasa perlu dilalui setiap hari tidak kira sama ada menggunakan bahasa pertama atau bahasa kedua. Proses penerimaan bahasa Melayu sebagai bahasa kedua bukanlah hadir secara semula jadi tetapi perlu dipelajari khususnya aspek kemahiran membaca dan menulis (Khairul Nizam Mohamed Zuki, 2017). Pengetahuan tentang aspek berkaitan kedua-dua kemahiran tersebut hanya dikuasai oleh murid bukan penutur natif menerusi tatacara pemerolehan, iaitu dikuasai secara tidak formal dalam persekitaran keluarga, dan lebih merupakan sebahagian daripada sistem pendidikan (Ellis, 2008). Bagi murid bukan penutur natif aspek kecekapan bahasa dikuasai menerusi pembelajaran formal di sekolah (Zulkifley Hamid, 2014). Dalam konteks bahasa kedua, pemerolehan hanya akan dicapai apabila bahasa kedua dipraktikkan sejak awal kanak-kanak untuk membentuk kebiasaan kerana bahasa Melayu merupakan bahasa ilmu, bahasa perpaduan dan bahasa rasmi Malaysia.

Murid bukan Melayu menguasai bahasa pertama atau bahasa ibundanya secara semula jadi dalam persekitaran dan budaya linguistiknya. Proses membina kemahiran berbahasa kedua dilakukan secara formal sebagai kemahiran tambahan (Khairul Nizam Mohamed Zuki, 2017). Terdapat perbezaan antara kemahiran baharu dengan kemahiran sedia ada yang menggunakan bahasa ibunda (Zulkifley Hamid, 2014).

Murid tahap dua di sekolah rendah seharusnya sudah boleh membaca secara sendirian untuk memahami, mengingat, mentafsir, menghurai dan menilai konsep, mengumpul maklumat, menghubung kait idea, dan membuat rumusan bagi setiap bahan bacaan yang dibacanya kerana kemahiran membaca dan kefahaman

Pengajaran Bahasa Melayu dalam Kalangan Pelajar Asing: Analisis Pola Kesalahan Tatabahasa dalam Penulisan 
merupakan salah satu kemahiran yang sangat penting dalam menentukan kejayaan pembelajaran seseorang individu.

Pencapaian bahasa Melayu di Sekolah Jenis Kebangsaan (SJK) juga kian merosot akibat kelunturan penguasaan kemahiran berbahasa Melayu belakangan ini. Dapatan kajian lepas menunjukkan bahawa murid bukan penutur natif di Malaysia kurang lancar membaca menggunakan bahasa kebangsaan (Chew, 2016). Menurut Nora'azian (2018), penyelidikan berkaitan kecekapan bahasa Melayu penting dijalankan dengan memfokuskan murid di sekolah rendah bagi menyediakan satu landasan awal dalam kalangan murid yang pelbagai etnik di Malaysia. Usaha untuk memartabatkan bahasa Melayu hanya boleh dicapai jika setiap individu menguasai keempat-empat kemahiran iaitu kemahiran mendengar, kemahiran bertutur, kemahiran membaca dan kemahiran menulis dengan baik. Namun kertas kerja ini memfokuskan kemahiran membaca dan menulis sahaja. Pemahaman input bahasa lisan dan bertulis dilihat sebagai satu-satunya mekanisme yang menyebabkan peningkatan kecekapan linguistik asas untuk melahirkan generasi yang kompeten dalam bahasa Melayu.

Jelasnya, dapat dirumuskan permasalahan persekitaran merupakan fenomena yang berlaku akibat amalan sistem persekolahan dan pembentukan bahasa dalam kalangan murid bukan penutur natif. Kurangnya motivasi belajar bahasa Melayu dalam kalangan murid bukan penutur natif kerana mereka menganggap bahawa bahasa Melayu kurang penting dalam kehidupan. Hal ini merupakan faktor murid tidak lancar membaca dan tidak mahir menulis dalam bahasa Melayu. Amalan penggunaan percampuran kod dan pengalihan kod daripada masyarakat yang multietnik juga penyumbang kepada permasalahan dalam penguasaan kedua-dua kemahiran ini. Kajian perlu dijalankan selari dengan Anjakan Kedua Pelan Pembangunan Pendidikan Malaysia (2013-2025) supaya setiap murid cekap dalam bahasa Melayu. Kecekapan berbahasa Melayu perlu dijadikan wadah utama untuk membangunkan bangsa sesebuah negara dalam membina tamadun Malaysia moden.

\section{Tinjauan Literatur}

Kajian berkaitan kemahiran menulis telah dijalankan oleh Noor Habsah Ali (2018) berkaitan strategi pembelajaran kemahiran menulis bahasa Melayu sebagai sebagai bahasa kedua dalam kalangan pelajar Melanau. Hasil dapatannya menunjukkan tidak terdapat hubungan signifikan antara penggunaan strategi pembelajaran bahasa Melayu. Dapatan ini membuktikan bahawa penggunaan strategi pembelajaran kemahiran menulis dengan pencapaian pelajar etnik Melanau dalam pelajaran bahasa Melayu. Dapatan ini membuktikan bahawa penggunaan strategi pembelajaran semata-mata. Implikasi kajiannya juga menunjukkan bahawa pencapaian akademik pelajar etnik Melanau berada pada tahap sederhana. Namaun bagi menjawab soalan-soalan peperiksaan awam di Malaysia pelajar perlu menguasai strategi pembelajaran yang disarankan seperti mengintegrasikan teknologi seperti Internet untuk mendedahkan mereka kepada pembelajaran bahasa selaras dengan kemahiran abad ke-21.

Pengajaran Bahasa Melayu dalam Kalangan Pelajar Asing: Analisis Pola Kesalahan Tatabahasa dalam Penulisan 
Masalah utama kemahiran menulis terutama murid tahap 1 di SJKT ialah responden didapati sukar untuk membezakan huruf. Mereka amat keliru dengan bentuk-bentuk huruf yang hampir sama seperti $(n-m),(g-p)$ dan (c-e). Huruf terbalik $(m-w),(n-u)$ dan huruf songsang $(b-d),(q-p)$, dan (b-p). Rata-rata responden tidak memahami struktur bahasa Melayu. Oleh itu, mereka menyusunnya sesuka hati tanpa mengira subjek atau predikat. Murid juga tidak memahami struktur ayat, dan tidak memahami pola ayat dalam bahasa kedua terutama bahasa Melayu. Kajian Noor Zila Md. Yusuf (2015) juga mendapati dalam situasi sebenar murid bukan penutur natif di SJKC, menghadapi masalah yang hampir sama, tidak dapat mengaplikasikan kemahiran menulis dalam bahasa Melayu. Pengajaran guru berfokuskan pemindahan fakta dan mengingat kembali untuk tujuan peperiksaan semata-mata. Kebanyakan murid akan menghafal rumus-rumus tatabahasa, karangan contoh dan menggunakan bahasa Antara dalam penulisan mereka.

Begitu juga dengan dapatan kajian Norsimah Mat Awal, Nadrah Abu Bakar, dan Norhashimah Jalaluddin (2012). Majoriti pencapaian akademik bagi kemahiran menulis murid bukan Melayu di Sekolah Menengah Kebangsaan (SMK) adalah pada tahap sederhana dan lebih daripada 20\% adalah lemah. Dapatan beliau mendapati murid Cina di SMK kurang berminat membaca dan menulis dalam bahasa Melayu kerana menganggap penggunaan bahasa Melayu tidak penting dalam kehidupan ataupun kerjaya. Mereka mempelajari bahasa Melayu semata-mata untuk mendapatkan sijil dalam peperiksaan awam yang menjadi syarat wajib bagi semua pelajar di Malaysia. Mereka menganggap mereka tidak perlu cekap dalam berbahasa Melayu kerana bahasa Melayu sebagai bahasa untuk berkomunikasi secara santai sahaja. Lagipun penggunaannya yang sangat terhad semasa mempelajari subjek bahasa Melayu di dalam kelasa sahaja. Tambahan pula alat artikulasi mereka sudah biasa dengan bahasa ibunda sejak di sekolah rendah lagi. Tahap penggunaan bahasa Melayu yang dilihat semakin luntur penggunaannya akibat pengaruh bahasa bahasa ibunda dan bahasa Inggeris merupakan salah satu faktor kajian perlu dijalankan bagi meningkatkan kemampuan berbahasa kebangsaan bagi murid bukan penutur natif. Kajian Noor Zila Md Yusuf (2015) juga mendapati kebanyakan murid India hanya menghafal rumus-rumus tatabahasa, karangan contoh dan menggunakan bahasa Antara dalam penulisan mereka.

Kajian Abdul Rasid Jamian (2011) mendapati murid Cina di sekolah rendah luar bandar masih tidak dapat membunyikan perkataan dengan tepat dan betul, tidak dapat menyebut perkataan yang dieja dengan betul dan sering meninggalkan perkataan yang tidak diketahui maknanya atau gagal membunyikannya. Hal ini menimbulkan pola bacaan yang merangkak-rangkak dan pastinya menjadikan murid tidak memahami maklumat dan makna bahan bacaan tersebut. Selain itu, murid yang lemah dan tidak berminat mencari maklumat yang tercatat dalam bahan rangsangan yang diberi oleh guru menyebabkan pencapaian akademik terutama bahasa Melayu kurang memuaskan. Ketidakupayaan murid menguasai kemahiran membaca, pasti memberikan masalah untuk menguasai kemahiran mendengar, bertutur, dan menulis kerana murid kurang terdedah dengan bahasa Melayu dalam persekitaran kehidupan mereka. Kajian tentang tahap penguasaan membaca dan menulis murid terutama di SJKC dan di SJKT sama ada di bandar atau di luar bandar perlu dikaji bagi meningkatkan tahap profesiensi dalam bahasa Melayu.

Pengajaran Bahasa Melayu dalam Kalangan Pelajar Asing: Analisis Pola Kesalahan Tatabahasa dalam Penulisan 
Chew (2016) pula telah menjalankan kajian berkaitan dengan kemahiran membaca kepada murid-murid Cina di SJKC dan murid-murid Cina di Sekolah Kebangsaan (SK). Dapatan menunjukkan murid-murid Cina menghadapi masalah sebutan kerana kurang membaca buku atau bahan bacaan bahasa Melayu. Mereka juga kurang gemar membaca bahan bacaan atau buku bahasa Melayu kerana faktor kebudayaan, pengaruh rakan dan keluarga. Selain itu, murid-murid Cina sering melakukan kesalahan sebutan fonem ( $m, n, l$, dan $r$ ) dan konsonan bergabung (sy, ny, dan ng) menyebabkan mereka sering melakukan kesalahan ejaan dalam penulisan sama ada binaan ayat, menulis rumusan dan karangan dalam subjek Bahasa Melayu Penulisan. Responden juga sering menghadapi masalah dengan sistem bahasa bagi menjawab Bahasa Melayu Pemahaman di sekolah rendah. Dapatan kajiannya menunjukkan kebanyakan murid murid Cina sama ada di SJKC atau di SK jarang menggunakan buku dan bahan bacaan berbahasa Melayu sebagai sumber utama dalam memperoleh ilmu pengetahuan. Sehubungan itu, murid Cina sering menghadapi masalah untuk menguasai sebutan dalam bacaan dan penulisan dalam bahasa Melayu.

Jelasnya, hasil dapatan daripada pengkaji-pengkaji lepas menunjukkan fenomena semasa menunjukkan bilangan murid yang lemah membaca dan menulis telah menjangkau lebih daripada 500,000 orang dan kebanyakannya terdiri daripada murid Tahun 6. Jumlah ini mewakili $25 \%$ daripada dua juta orang murid sekolah rendah di Malaysia. Pernyataan ini menunjukkan bahawa tahap membaca dan menulis murid di sekolah rendah masih pada tahap yang membimbangkan. Jelasnya, penguasaan kemahiran membaca dan menulis terbukti kepentingannya dalam sistem pendidikan yang mementingkan pencapaian akademik sebagai ukuran kejayaan pendidikan individu. Kajian dijalankan untuk melihat tahap kefahaman bacaan menggunakan instrumen kajian Ujian Membaca UPBM_SR dan Ujian Menulis UPBM_SR kepada murid Tahap 2 yang seharusnya sudah menguasai keduadua kemahiran dalam bahasa Melayu (DSKP, KPM, 2013).

\section{Pernyataan Masalah}

Kajian berkenaan kemahiran dalam bahasa Melayu (Abdul Rasid, 2011; Chew, 2016) bagi kemahiran membaca mendapati murid di sekolah rendah terutama di luar bandar masih kurang lancar membaca dalam bahasa Melayu manakala penyelidik lain (Noor Habsah Ali, 2018; Noor Zila Md Yusuf, 2015; Norshimah et al., 2012) mendapati majoriti pencapaian akademik bagi kemahiran menulis murid bukan Melayu di Sekolah Menengah Kebangsaan (SMK) pula pada tahap sederhana dan lebih $20 \%$ adalah lemah. Kajian ini dijalankan untuk keperluan pengenalpastian dan pengesahan terhadap kajian yang dinyatakan bagi meningkatkan prestasi akademik murid di SJK.

Berdasarkan Senarai Sekolah Mengikut Kumpulan Jenis dan Negeri (Mei 2014), oleh Kementerian Pendidikan Malaysia, Kuantan merupakan antara 4 Daerah yang mempunyai bilangan SJKC dan SJKT tertinggi di Pahang iaitu sebanyak 15 buah sekolah manakala Daerah Bentong 17 buah, Temerloh 17 buah, dan Cameron Highlands 16 buah. Oleh hal yang demikian SJK Daerah Kuantan dipilih sebagai lokasi kajian kerana pemilihan murid di SJKC dan di SJKT amat kurang dijalankan sebagai

Pengajaran Bahasa Melayu dalam Kalangan Pelajar Asing: Analisis Pola Kesalahan Tatabahasa dalam Penulisan 
pemaklum kajian. Kajian juga dijalankan di Daerah Kuantan supaya kajian lebih berfokus untuk mengetahui masalah sebenar yang dihadapi oleh murid yang belajar di SJK. Sekiranya hal ini tidak diberikan perhatian serius, kemungkinan besar murid bukan penutur yang gagal menguasai kedua-dua kemairan tersebut akan terus meningkat.

Jadual 1

Keputusan Peperiksaan UPSR di SJK Daerah Kuantan bagi Tahun 2012, 2013, dan 2014

\begin{tabular}{cccc}
\hline $\begin{array}{c}\text { Tahun/ } \\
\text { Jenis } \\
\text { Sekolah }\end{array}$ & \multicolumn{3}{c}{ Gred Purata Sekolah (GPS) } \\
\hline 2012 & BM- Pemahaman & BM-Penulisan & Keseluruhan Subjek \\
\hline SJKC & 2.7 & 2.6 & 2.4 \\
SJKT & 2.9 & 2.9 & 2.3 \\
\hline 2013 & BM- Pemahaman & BM-Penulisan & Keseluruhan Subjek \\
\hline SJKC & 2.5 & 2.5 & 2.4 \\
SJKT & 2.6 & 2.5 & 2.1 \\
\hline 2014 & BM- Pemahaman & BM-Penulisan & Keseluruhan Subjek \\
\hline SJKC & 2.3 & 3.0 & 2.3 \\
SJKT & 3.1 & 3.0 & 2.6 \\
\hline
\end{tabular}

(Sumber: Pejabat Pendidikan Daerah Kuantan, Pahang)

Berdasarkan Jadual 1, Gred Purata Sekolah (GPS) bagi keputusan Peperiksaan UPSR murid di SJK Daerah Kuantan dari tahun 2012 hingga 2014 didapati pencapaian mata pelajaran bahasa Melayu semakin menurun. Pada Tahun 2014 kedua-dua jenis sekolah mencatatkan penurunan GPS bagi subjek BMPenulisan dan BM-Pemahaman. Analisis ini menunjukkan bahawa tahap kecekapan kemahiran menulis, dan membaca murid bukan penutur natif semakin membimbangkan. Usaha untuk meningkatkan profesiensi bahasa Melayu dalam kalangan murid Cina dan India perlu dilakukan untuk meningkatkan pencapaian akademik terutama subjek Bahasa Melayu di SJK.

Berdasarkan permasalahan yang disenaraikan, jelas menunjukkan keperluan kajian terhadap profesiensi bahasa Melayu. Fenomena ini harus diberikan perhatian yang serius memandangkan penguasaan tahap profesiensi bahasa Melayu terutama kemahiran membaca dan menulis dalam bahasa kedua perlu disemai bermula di peringkat awal kanak-kanak lagi. Pemahaman input bahasa lisan dan bertulis dilihat sebagai satu-satunya mekanisme yang menyebabkan peningkatan profesiensi linguistik asas. Output bahasa dianggap tidak membawa apa-apa kesan dan hanya maju apabila bahasa diperoleh secara separa sedar. Pembelajaran sedar tidak boleh digunakan sebagai sumber hasil bahasa yang spontan (Zulkifley Hamid, 2014).

Pengajaran Bahasa Melayu dalam Kalangan Pelajar Asing: Analisis Pola Kesalahan Tatabahasa dalam Penulisan 


\section{Objektif Kajian}

Kajian ini dijalankan untuk mencapai perkara-perkara berikut:

1) mengenal pasti tahap profesiensi kemahiran membaca dalam kalangan murid bukan penutur natif di SJK Daerah Kuantan.

2) Mengenal pasti tahap profesiensi kemahiran menulis dalam kalangan murid bukan penutur natif di SJK Daerah Kuantan.

\section{Metodologi Kajian}

Kajian ini menggunakan kaedah pengumpulan data secara kuantitatif dengan reka bentuk tinjauan keratan rentas (cross-sectional). Dua instrumen yang diguna pakai untuk mendapatkan data iaitu Ujian Profesiensi UPBM_SR yang terdiri daripada Ujian Membaca UPBM_SR dan Ujian Mendengar UPBM_SR. Skor markah yang diperoleh oleh responden daripada kedua-dua ujian tersebut akan diperingkatkan menggunakan Tahap Skor UPBM_SR.

\section{Responden kajian}

Berdasarkan kaedah pemilihan sampel Krejcie dan Morgan (1970) persampelan rawak sistematik digunakan. Sampel diperoleh dengan memilih unsur secara rawak. Penyelidik mendapatkan senarai kesemua subjek yang berkemungkinan untuk dipilih. Pemilihan data adalah dibuat dengan memilih setiap $m$ sampel daripada senarai data tersebut (merupakan senarai data sampel yang diperlukan). Cara pengambilan persampelan ini adalah dengan hanya unsur atau bilangan data pertama dipilih secara rawak manakala bilangan data berikutnya dipilih secara sistematik mengikut suatu pola tertentu. Kaedah ini dilakukan dengan memilih subjek kajian berdasarkan selang. Pengiraan dilakukan dengan cara: senarai data $=$ 3,252 , data sampel diperlukan $=414$, maka $\mathrm{k}=8$. Bagi memilih data yang pertama, satu nombor dari $1-8$ dipilih secara rawak. Penyelidik memilih nombor 3 , maka nombor seterusnya adalah $3+8=11$ (dan nombor yang seterusnya adalah $11+8$, $19+8,27+8$ dan seterusnya). Jumlah populasi kajian (murid bukan penutur natif tahap 2 di SJK di Daerah Kuantan adalah seramai 3,252 orang.

$$
\text { Formula }=\frac{\text { Bilangan populasi }}{\text { Bil Sampel }} \quad N=414 \text { orang }
$$

Responden yang dikaji seramai 198 orang (47.1\%) murid lelaki dan 222 orang (52.9\%) murid perempuan. Sebanyak 268 berbangsa Cina manakala India seramai 146 sahaja kerana SJKT merupakan Sekolah Kurang Murid (SKM). Responden paling ramai dipilih dari kalangan murid tahun 6 iaitu seramai 334 orang yang telah selesai menjalani peperiksaan UPSR pada tahun tersebut. Sebagai memenuhi ruang masa pada masa kutipan data dibuat, pihak sekolah meminta pengkaji memberikan ujian UPBM_SR kepada murid Tahun 6 manakala murid Tahun 5 hanya seramai 61 orang dan murid Tahun 4 seramai 27 orang yang kebanyakan dari SJKT. Responden dipilih daripada murid tahap 2 yang telah menguasai keempat-empat kemahiran dalam BM

Pengajaran Bahasa Melayu dalam Kalangan Pelajar Asing: Analisis Pola Kesalahan Tatabahasa dalam Penulisan 
iaitu kemahiran mendengar, bertutur, membaca, dan menulis. Pemilihan reponden dibuat oleh guru yang mengajar Bahasa Melayu di sekolah tersebut.

\section{Instrumen Kajian}

Instrumen yang digunakan ialah Ujian Profesiensi Bahasa Melayu Sekolah Rendah (UPBM_SR) yang terdiri daripada Ujian Membaca UPBM_SR dan Ujian Menulis UPBM_SR. Kedua-dua intrumen kajian dan Tahap Skor UPBM_SR telah dibangunkan dengan proses adaptasi dan penyesuaian.

Pembangunan instrumen, UPBM_SR telah melalui lima peringkat iaitu peringkat persediaan ujian, pemeriksaan dan pengukuran, analisis ujian, interpretasi dan tindakan susulan (Azizi Ahmad \& Mohd Isa Awang, 2008). Pertama, peringkat persediaan ujian, UPBM_SR dibangunkan berdasarkan kerangka Ujian Kecekapan Bahasa Melayu (UKBM), rujukan Silibus-silibus bahasa Melayu Lembaga Peperiksaan, Kementerian Pelajaran Malaysia (KPM), rujukan format soalan-soalan kefahaman Ujian Profesiensi Bahasa Inggeris TOEFL Junior dan IELTS Junior. Kedua peringkat pemeriksaan dan pengukuran, menggunakan Formula Kebolehbacaan Petikan Bahasa Melayu Khadijah Rohani Mohd. Yunus (2001) dan Ujian Kloz untuk mengukur tahap kesukaran atau kebolehbacaan bahan setiap teks petikan Ujian Membaca UPBM_SR dan Ujian Menulis UPBM_SR. Ketiga, analisis ujian, kedua-dua proses dijalankan melalui kajian rintis untuk memastikan kesahan dan kebolehpercayaan teks petikan. Kedua-dua formula juga digunakan untuk melihat kesesuaian teks dari segi pemilihan perkataan bahasa Melayu kepada murid bukan penutur natif di SJK dan kesesuaian umur bacaan (Juntos, 2002). Keempat, peringkat interpretasi hasil kajian rintis. Kelima, tindakan susulan. Instrumen kajian yang dibangunkan dirujuk kepada ahli panel penilai.

\section{Ujian membaca UPBM_SR.}

Ujian Membaca dilaksanakan untuk mengenal pasti tahap kelancaran membaca, memahami perkataan sukar, menaakul dan kebolehan murid memindahkan maklumat dari pelbagai bahan bacaan untuk menjawab soalan pemahaman daripada petikan yang disediakan.

\section{Ujian Menulis UPBM_SR}

Ujian Menulis UPBM_SR dilaksanakan bertujuan mengenal pasti tahap kemahiran menulis murid bukan penutur natif menghasilkan penulisan kreatif pelbagai genre menggunakan perkataan dan kosa kata yang pelbagai dan kompleks, serta menggunakan sistem bahasa dengan yang tepat pada tahap sangat terperinci.

\section{Tahap skor UPBM_SR.}

Tahap skor dan skor rubrik untuk UPBM_SR telah dibina dengan menyemak dan mengadaptasi rubrik yang sedia ada. Tahap Skor dan rubrik untuk UPBM_SR akan menentukan skor murid bukan penutur natif dalam UPBM_SR. Oleh itu, penyelidik

Pengajaran Bahasa Melayu dalam Kalangan Pelajar Asing: Analisis Pola Kesalahan Tatabahasa dalam Penulisan 
menggunakan skor membaca dan skor menulis UPBM_SR untuk mengukur tahap profesiensi membaca dan menulis reponden dalam bahasa Melayu.

\section{Kesahan dan kebolehpercayaan instrumen.}

Kesahan Instrumen Ujian Membaca dan Ujian Menulis UPBM_SR diuji untuk memastikan tahap pencapaian, kecekapan atau kecekapan diberi markah atau gred yang setara (penentusahan aras keputusan ujian) dengan kebolehan sebenar responden yang menduduki ujian (Fadzilah Abd Rahman, Zuraini Jusoh, dan Norazlina Mohd Kiram, 2016). Antara aspek yang diberikan perhatian termasuk pembangunan prosedur pengujian, kesesuaian penggunaan alat pengujian, dan pengendalian pengujian. Kesahan dan kebolehpercayaan item-item Ujian Membaca dan Ujian Menulis UPBM_SR telah dijalankan untuk menitikberatkan keadilan kepada semua responden yang menduduki Ujian UPBM_SR. Bagi tujuan kesahan muka (face validity) dan kesahan kandungan (content validity) instrumen kajian telah diuji dalam kajian rintis. Komen dan teguran yang diterima daripada pakarpakar penilai juga telah diambil kira dan diguna pakai bagi memantapkan maksud, bahasa, kandungan, tema, pengolahan, dan persembahan dalam Ujian Standard Menulis UPBM_SR.

Kertas jawapan Ujian Membaca dan Ujian Menulis responden disemak oleh guru pemeriksa kertas UPSR berdasarkan skema jawapan yang disediakan oleh penyelidik dan rujukan Rubrik UPBM_SR. Bagi tujuan penyelarasan kertas-kertas jawapan Ujian Menulis disemak semula oleh ketua pemeriksa UPSR di Daerah Kuantan. Selain itu, perkara yang dipastikan oleh penyelidik bagi tujuan kebolehpercayaan pentadbiran Ujian Standard Menulis UPBM_SR ialah mengemukakan dua soalan iaitu Bahagian A; bina ayat dan Bahagian B: menulis karangan. Responden diberikan lebih daripada satu soalan untuk menguji kecekapan menulis murid bukan penutur natif untuk memastikan ujian atau alat penilaian itu memberikan peluang kepada murid mengemukakan jawapan yang mencerminkan keupayaannya menulis. Skema yang standard dan selaras disediakan supaya pengujian dan pemberian markah dapat diselaraskan.

\section{Dapatan Kajian}

Skor markah Ujian Membaca UPBM_SR yang diperoleh responden diperingkatkan menggunakan Tahap Skor UPBM_SR bagi penentuan tahap. Tahap 1 merupakan tahap terendah, manakala Tahap 8 merupakan tahap tertinggi. Dapatan kajian telah menjawab soalan kajian.

\section{Tahap Kecekapan Kemahiran Membaca Murid Bukan Penutur Natif di SJK Daerah Kuantan}

Bagi menjawab soalan pertama kajian, Jadual 2 menunjukkan taburan tahap kelancaran membaca responden.

Pengajaran Bahasa Melayu dalam Kalangan Pelajar Asing: Analisis Pola Kesalahan Tatabahasa dalam Penulisan 
Jadual 2

Taburan tahap kemahiran membaca responden $(N=414)$

\begin{tabular}{llcc}
\hline Tahap & $\begin{array}{c}\text { Bilangan } \\
\text { Responden }(\boldsymbol{n})\end{array}$ & $\begin{array}{c}\text { Peratusan } \\
(\%)\end{array}$ \\
\hline 1 & Sangat Terbatas & 2 & 0.5 \\
2 & Terbatas & 63 & 15.2 \\
3 & Sangat Terhad & 99 & 23.9 \\
4 & Sederhana Lancar & 87 & 21.0 \\
5 & Hampir Lancar & 92 & 22.2 \\
6 & Lancar & 64 & 15.5 \\
7 & Lebih Lancar & 7 & 1.7 \\
8 & Paling Lancar & 0 & 0.0 \\
\hline & Jumlah & 414 & 100.0 \\
\hline
\end{tabular}

Sebanyak 39.6\% atau 164 orang responden mendapat Tahap 1 hingga Tahap 3. Murid bukan penutur natif masih kurang lancar dalam kemahiran membaca bahasa Melayu berdasarkan skor yang diperoleh daripada Ujian Membaca UPBM_SR yang telah diduduki. Purata skor markah yang diperoleh antara 10 hingga 30 . Responden hanya menunjukkan kemahiran membaca yang sangat terhad. Responden berkebolehan membaca, memahami ayat-ayat tertentu dalam bahan yang dibaca dan dapat memindahkan maklumat namun pada tahap yang sangat terhad. Sebanyak $15 \%$ hanya menguasai kemahiran asas membaca dan boleh memahami beberapa patah perkataan sahaja.

Responden yang mendapat tahap sederhana iaitu mendapat Tahap 4 dan Tahap 5 pula sebanyak 43.2\%. Seramai 179 orang murid mendapat skor markah antara 31 hingga 50. Responden menunjukkan kemahiran yang hampir lancar, berkebolehan membaca, memahami pelbagai bahan bacaan dan berkemampuan memahami perkataan-perkataan sukar, boleh menaakul dan memindahkan maklumat pada tahap sesuai. Murid dapat memilih antara jawapan yang betul dengan jawapan yang salah berdasarkan kemampuan mereka memahami maksud petikan, frasa dan kehendak soalan. Walau bagaimanapun, masih ramai calon hanya memahami perkataan-perkataan mudah dan hanya meneka jawapan aneka pilihan dalam Ujian Membaca UPBM_SR.

Walau bagaimanapun, hasil dapatan menunjukkan hanya $17.2 \%$ responden di SJK Daerah Kuantan yang menguasai kemahiran membaca pada Tahap 6 dan Tahap 7. Tiada responden yang memperoleh Tahap 8. Purata markah yang diperoleh antara 51 hingga 70. Markah penuh yang diperuntukkan bagi Ujian Membaca UPBM_SR ialah 80. Responden menunjukkan kemahiran membaca yang tinggi dan dapat memahami pelbagai bahan bacaan dengan lancar, berkemampuan memahamai perkataan-perkataan yang sukar dan pelbagai. Responden juga lancar menaakul dan memindahkan maklumat pada tahap kukuh dan terperinci.

Jelasnya tahap penguasaan kemahiran membaca murid bukan penutur natif di SJK Daerah Kuantan masih pada tahap yang sederhana walaupun telah enam tahun berada di sekolah rendah dan telah menduduki Peperiksaan Ujian Pencapaian Sekolah Rendah (UPSR).

Pengajaran Bahasa Melayu dalam Kalangan Pelajar Asing: Analisis Pola Kesalahan Tatabahasa dalam Penulisan 
Tahap Kecekapan Kemahiran Menulis Murid Bukan Penutur Natif di SJK Daerah Kuantan

Bagi menjawab persoalan kedua kajian, Jadual 3 menunjukkan taburan tahap kecekapan kemahiran menulis responden.

Jadual 3

Taburan Tahap Kemahiran Menulis Responden ( $N=414)$

\begin{tabular}{clcc}
\hline & Tahap & $\begin{array}{c}\text { Bilangan } \\
\text { Responden }(\boldsymbol{n})\end{array}$ & Peratusan (\%) \\
\hline 1 & Sangat Terbatas & 104 & 25.1 \\
2 & Terbatas & 82 & 19.8 \\
3 & Sangat Terhad & 84 & 20.3 \\
4 & Sederhana Mahir & 60 & 14.5 \\
5 & Hampir Mahir & 42 & 10.1 \\
6 & Mahir & 30 & 7.2 \\
7 & Lebih Mahir & 12 & 2.9 \\
8 & Paling Mahir & 0 & 0.0 \\
\hline & Jumlah & 414 & 100.0 \\
\hline
\end{tabular}

Berdasarkan dapatan kajian, majoriti responden mendapat Tahap 1 hingga Tahap 3 iaitu sebanyak 65.2\%. Purata markah yang diperoleh adalah antara 13 hingga 39. Responden hanya menunjukkan kemahiran menulis dan mengedit pada tahap yang kurang tepat. Responden hanya mampu menulis ayat-ayat pendek berdasarkan bahan rangsangan, menggunakan sistem bahasa yang betul pada tahap yang sangat terhad. Keseluruhan responden tidak menunjukkan penguasaan kemahiran menulis. Kebanyakan hanya menyalin soalan, dan menulis ayat-ayat yang dihafal semula untuk menjawab soalan BM-Penulisan dalam Peperiksaan UPSR yang lalu berdasarkan tema. Ayat-ayat yang dihasilkan oleh murid bukan penutur natif juga kurang gramatis dan ada yang hanya menyalin soalan.

Murid yang mendapat Tahap 4 dan Tahap 5 bagi Ujian Menulis UPBM_SR hanya $24.6 \%$. Purata markah yang diperoleh antara 40 hingga 65. Responden menunjukkan kemahiran menulis dan mengedit pada tahap yang memuaskan. Murid mampu menggunakan perkataan dan kosa kata yang masih tepat, menggunakan sistem bahasa yang betul pada tahap yang terhad dan ada yang berkemampuan menggunakan perkataan pada tahap kukuh. Namun daripada binaan ayat menunjukkan ayat-ayat tersebut adalah hasil hafalan berdasarkan tema sebagai persediaan untuk menduduki peperiksaan UPSR.

Murid yang mendapat Tahap 6 dan Tahap 7 dalam Ujian Menulis UPBM_SR hanya $10.1 \%$ dengan purata markah yang diperoleh antara 66 hingga 91 . Tiada responden yang mendapat markah Tahap 8 antara 92 hingga 104. Jelasnya, kemahiran menulis merupakan kemahiran yang paling kritikal bagi murid bukan penutur natif di SJK. Masih kedapatan hampir tiga perempat murid di SJK yang tidak mahir menulis menggunakan bahasa Melayu standard. Fenomena ini amat membimbangkan.

Pengajaran Bahasa Melayu dalam Kalangan Pelajar Asing: Analisis Pola Kesalahan Tatabahasa dalam Penulisan 


\section{Perbincangan}

Dapatan kajian menunjukkan kedua-dua tahap kecekapan murid bukan penutur natif di SJK adalah pada tahap yang sederhana. Kebanyakan murid Tahap 2 di SJK masih tidak menguasai kemahiran asas membaca dan menulis dalam bahasa Melayu. Ketidakupayaan murid menguasai kemahiran membaca, memberikan masalah untuk murid memahami petikan Ujian Membaca UPBM_SR. Selain itu, murid juga lemah untuk mengesan isi yang terdapat di dalam petikan menyebabkan mereka mengambil jalan mudah untuk menjawab tanpa membaca soalan yang disediakan. Ketidaklancaran membaca bahasa Melayu juga sering dikaitkan dengan pencapaian akademik yang rendah. Murid yang masih kurang kukuh dalam kemahiran membaca pasti menjejaskan pencapaian bagi semua subjek kerana kemahiran membaca asas bagi memperoleh maklumat.

Berdasarkan dapatan kajian ini, penguasaan kemahiran membaca dan kemahiran menulis bahasa Melayu murid bukan penutur natif di SJK Daerah Kuantan, jelas menunjukkan murid Cina dan murid Tamil keliru dengan bahasa ibunda. Hal ini disebabkan mereka telah menguasai kemahiran membaca dan menulis dalam bahasa ibunda sejak di tadika lagi. Mereka juga menggunakan bahasa vernakular sebagai bahasa pengantar di sekolah dan menggunakan bahasa ibunda yang pelbagai dialek dalam komunikasi seharian. Dari segi penulisan pula, murid Cina juga didapati keliru dengan penggunaan huruf-huruf aksara yang digunakan dalam bahasa Melayu sedangkan dalam penulisan bahasa Mandarin menggunakan huruf "Kai Ti" manakala aksara yang digunakan dalam bahasa Tamil ialah Sellinam. Murid Cina dan India juga didapati amat kurang membaca buku-buku dalam bahasa Melayu menyebabkan tahap kecekapan mereka pada tahap yang sederhana. Kajian selari dengan (Chew, 2016) yang memfokuskan kepada permasalahan sebutan dan kemahiran menulis murid Cina di SK dan di SJK (C).

Berdasarkan hasil dapatan juga tahap bagi kemahiran menulis dilihat sebagai satu kemahiran yang paling kritikal di SJK kerana terdapat $65 \%$ responden yang tidak mahir menulis menggunakan bahasa Melayu. Majoriti mendapat Tahap 1 hingga Tahap 3 iaitu boleh dikategorikan lemah berdasarkan Tahap Skor UPBM_SR bagi kemahiran menulis. Murid bukan penutur natif dilihat tidak dapat menghuraikan idea dengan baik malah menggunakan perkataan-perkataan daripada bahasa ibunda untuk menggambarkan idea yang diketengahkan. Kedapatan juga murid menggunakan perkataan bahasa Inggeris bagi perkataan yang tidak diketahuinya. Secara keseluruhan ramai responden yang memperoleh peringkat memuaskan. Mereka hanya menggunakan ayat mudah dan ringkas berdasarkan bahan grafik. Ramai responden yang mendapat tahap minimum kerana ayat yang ditulis tidak sesuai dengan bahan grafik, penggunaan perkataan yang terhad, tidak menguasai kemahiran tanda baca dan sistem ejaan baku. Situasi ini selari dengan kajian Noor Habsah Ali (2018) terhadap pelajar tingkatan 4 etnik Melanau daripada tiga buah sekolah menengah di Daerah Daro, Sarawak. Pelajar bukan Melayu tidak dapat menghuraikan idea kerana kekurangan kosa kata dan pengaruh bahasa ibunda.

Keseluruhan dapatan bahagian B, murid bukan penutur natif tahap 2 adalah peringkat memuaskan. Mereka boleh menulis dan idea masih menepati tugasan dengan pengolahan idea yang ringkas dan mudah. Penyampaian yang masih

Pengajaran Bahasa Melayu dalam Kalangan Pelajar Asing: Analisis Pola Kesalahan Tatabahasa dalam Penulisan 
menarik. Penggunaan ayat kurang gramatis tetapi berkaitan dengan tugasan. Penggunaan kata dan kosa kata yang sederhana. Terdapat banyak kesalahan ejaan dan tanda baca. Rata-rata tidak menguasai kemahiran penggunaan ejaan dan tanda baca. Penggunaan ayat yang tidak gramatis dan tidak menguasai kemahiran penggunaan ejaan dan tanda baca. Masih kedapatan responden yang tidak boleh menggabungkan suku kata, klausa dan frasa untuk membentuk perkataan. Murid juga tidak menguasai struktur subjek dan predikat ayat. Responden masih tidak memahami pola ayat. Dapatan kajian selari dengan kajian Muhammad Saiful (2012) terhadap murid Tahap 1.

Selain itu, masalah utama murid dalam kemahiran menulis ialah tidak dapat membezakan huruf besar dengan huruf kecil, tidak dapat mengecam abjad, tidak memahami maklumat yang ditulis, tidak mengenal pasti tanda baca semasa menghasilkan penulisan. Kegagalan responden menguasai kemahiran mekanikal menulis menyebabkan murid tidak dapat membina ayat dan melahirkan idea dalam penulisan karangan pada Bahagian B iaitu membina karangan. Sesuatu latihan dengan baik. Hal ini sudah pasti menjejaskan penghasilan penulisan karangan kerana murid tidak menguasai kemahiran asas dalam menulis. Keadaan ini ditambah lagi kerana kelemahan murid menguasai kemahiran membaca dengan baik menyebabkan responden tidak dapat mengeja perkataan dengan baik untuk dizahirkan semasa menulis. Kajian selari dengan dapatan (Abdul Rashid Jamian, 2011) terhadap murid di sekolah rendah luar bandar.

Berdasarkan dapatan kajian Ujian Menulis UPBM_SR, responden juga didapati tidak mampu menggunakan perkataan yang tepat dalam BM. Justeru, mereka akan menggunakan istilah dalam bahasa ibunda yang mampu membawa makna seperti yang ingin disampaikan dalam penulisan mereka. Keadaan ini sudah pasti menimbulkan masalah apabila responden berfikir dalam B1 dan seterusnya menterjemahkan idea mereka ke dalam bahasa kedua. Gaya retorik kedua-dua bahasa yang berbeza berkemungkinan menghasilkan penulisan yang tidak mematuhi retorik bahasa kedua kerana kecekapan menulis perlu dipelajari, bukan sahaja dari segi bentuk dan corak yang berbeza malah gaya bahasa dan penyampaian yang berbeza.

Antara masalah kritikal yang dihadapi oleh responden dalam Ujian Menulis UPBM_SR ialah idea tidak dikembangkan kerana kosa kata terhad, masalah ejaan, imbuhan, kesalahan tatabahasa, tanda baca, struktur ayat, penjodoh bilangan, kesalahan tatabahasa, penjodoh bilangan, percampuran kod dan kekurangan skil menulis karangan. Karangan murid terutama di SJKC stereotaip kerana dihafal oleh murid. Terdapat juga karangan yang terpesong kerana responden hanya menulis semula karangan yang dihafal untuk setiap kali peperiksaan. Murid akan menghafal karangan mengikut tema. Murid akan menulis semula di dalam peperiksaan tanpa memahami kehendak soalan. Setiap murid akan menulis jawapan yang sama dan melakukan kesalahan yang sama bagi setiap murid. Faktor lain yang dapat dikenal pasti adalah kerana mereka amat kurang membaca buku dalam bahasa Melayu. Murid akan menghafal rumus tatabahasa dan karangan bagi menghadapi peperiksaan.

Pengajaran Bahasa Melayu dalam Kalangan Pelajar Asing: Analisis Pola Kesalahan Tatabahasa dalam Penulisan 


\section{Cadangan}

Kecekapan menulis perlu dipupuk pada awal usia kanak-kanak agar mereka dapat menguasainya secara semula jadi (Mahzan Arshad, 2016). Walau dalam apa-apa jua keadaan sekalipun, guru perlu membentuk profesiensi menulis dalam bahasa Melayu sejak sekolah rendah supaya menjadi kebiasaan dalam kehidupan seharian. Antara aktiviti yang dicadangkan ialah penulisan jurnal. Murid bukan penutur natif perlu diberikan kebebasan untuk menulis tentang catatan harian atau diari. Murid bukan penutur natif boleh melaporkan perkara-perkara yang berlaku setiap hari atau masa-masa yang tertentu dalam sesuatu hari, membuat tindak balas, menyatakan perasaan, pendapat, menilai, melukis, melabel, menentukan sebarang tindakan yang perlu diambil atau telah diambil. Kandungan jurnal lebih merupakan pemikiran murid tentang dirinya berhubung dengan perkara yang berlaku di dalam bilik darjah, baik dalam bentuk penulisan atau sebarang grafik yang dapat dibuat pada permukaan kertas dengan bimbingan format penulisan oleh guru supaya mereka melalui proses dalam menghasilkan karangan.

Tumpuan juga perlu diberikan kepada proses mengarang iaitu (merancang dan merangka) dan penghasilan karangan iaitu (menulis dan menyunting) Mahzan Arshad (2016). Menulis merupakan tahap paling tinggi dalam proses menghasilkan sesebuah karangan. Murid bukan penutur natif perlu digalakkan untuk menggunakan kecekapan yang tertinggi dalam memilih istilah yang akan digunakan, sesuai dengan laras karangan, membentuk frasa dan ayat-ayat yang beragam, serta menggunakan bahasa yang berkesan untuk ideanya. Selain idea yang banyak dan contoh yang jitu, murid bukan penutur natif perlu menguasai penguasaan bahasa yang tinggi, supaya proses menulis akan dapat berjalan dengan lancar. Kombinasi keempat-empat faktor utama, iaitu isi atau idea teknik penghujahan, kecekapan berbahasa dan keberkesanan dalam menghasilkan sebuah karangan yang bermutu tinggi perlu dikuasai oleh guru di SJK bagi meningkatkan tahap kecekapan bahasa Melayu sekali gus meningkatkan pencapaian akademik.

Kesempurnaan berbahasa tidak hanya dinilai dari segi penguasaan sistem bahasa, tetapi juga melibatkan pengetahuan tentang aspek luaran bahasa, iaitu budaya yang berperanan penting dalam pembinaan dan pemupukan sesuatu bahasa. Hal ini bersesuaian dengan keperluan penguasaan dalam kecekapan menulis. Penguasaan kecekapan tertinggi ini tidak hanya melibatkan aspek teknikal dan mekanikal semata-mata, tetapi penulisan turut melibatkan penggemblengan aspek psikologi dan kognitif. Pengetahuan kandungan pedagogi perlu dihayati kerana tubuh ilmu (body of knowledge) dan dicerakinkan menggunakan strategi yang sesuai dan terancang agar matlamat yang dikehendaki tercapai. Guru-guru bahasa Melayu juga perlu menggunakan strategi pembelajaran bahasa yang mantap terutama bagi pengajaran karangan dalam bahasa kedua supaya pemerolehan, penyimpanan, dan pemerolehan semula serta penggunaan maklumat dapat dijana bagi mempertingkatkan pencapaian dan penguasaan kecekapan menulis. Kompetensi profesional pendidik juga harus mencapai tahap yang ditetapkan oleh Standard Guru Malaysia (SGM) untuk menjamin dan mengekalkan pendidikan yang berkualiti kepada warga Malaysia kini dan akan datang.

Penyelidik mencadangkan agar kajian untuk meningkatkan tahap kecekapan menulis bahasa kedua terhadap murid bukan penutur natif di sekolah rendah

Pengajaran Bahasa Melayu dalam Kalangan Pelajar Asing: Analisis Pola Kesalahan Tatabahasa dalam Penulisan 
dijalankan secara meluas untuk membentuk jati diri bangsa Malaysia yang utuh dan sebati. Aktiviti PdPc bahasa kedua (B2) juga boleh disampaikan melalui bahasa pertama (B1) jika terdapat persamaan dengan bahasa kedua (B2). Dalam konteks kajian ini, persamaan yang ketara dalam kedua-dua bahasa dari segi bunyi, ejaan, dan maksud perkataan memudahkan murid memahami keseluruhan teks pemahaman. Maka aktiviti PdPc BM menggunakan bahasa ibunda adalah wajar dalam keadaan tertentu. Guru boleh menggunakan B1 apabila murid menghadapi kesukaran untuk memahami perkataan atau ayat dalam B2. Dalam hal ini, guru memainkan peranan agar murid tidak keliru untuk menentukan persamaan dan perbezaan yang wujud apabila pendedahan yang melibatkan kedua-dua bahasa dilakukan. Pengggunaan B1 secara sewenang-wenangnya akan membantutkan usaha menguasai bahasa kedua dalam kalangan murid. Justeru, guru perlulah berhati-hati agar aktiviti PdPc tidak dilakukan sepenuhnya dalam bahasa ibunda semasa PdPc BM. Oleh hal yang demikian adalah dicadangkan agar guru-guru yang mengajar BM dari kalangan penutur jati.

Selain itu, cadangan untuk menyokong dan menggalakkan murid bukan penutur natif meningkatkan kecekapan membaca dan menulis dengan strategistrategi berikut: Pertama, memberikan ejaan setiap kali memulakan pengajaran bahasa Melayu supaya murid bukan penutur natif dapat mendengar sebutan yang betul. Kedua, menggunakan kamus dwibahasa dengan kaedah dan cara yang menarik. Guru boleh menunjukkan gambar bagi kefahaman tentang sesuatu perkataan dalam bahasa kedua. Ketiga, mendedahkan dengan teknik menulis karangan. Guru-guru bahasa Melayu perlu kreatif dengan mencipta teknik-teknik menulis karangan yang menarik mengikut tahap kebolehan murid. Keempat, membimbing pengajaran penulisan juga perlu mengikut kaedah-kaedah yang dapat meningkatkan motivasi belajar kerana kecekapan menulis merupakan aktiviti yang memerlukan daya kritis dan kreatif yang tinggi, di samping penguasaan bahasa yang kukuh. Domain penulisan juga perlu sesuai dengan kaedah-kaedah yang telah dipelajari. Pengajaran penulisan yang diterapkan di dalam kelas melalui proses penulisan yang dapat membantu pelajar menguasai sesuatu kecekapan menulis. Guru di SJK juga perlu meningkatkan kecekapan menulis murid bukan penutur natif dengan memberikan latihan teknik penulisan yang berkesan di dalam bilik darjah.

\section{Kesimpulan}

Jelasnya, penguasaan kemahiran membaca dan menulis dalam bahasa kedua banyak bergantung kepada kesediaan murid sendiri untuk menerima dan mempelajarinya. Memandangkan, majoriti murid tahun 6 hanya menguasai kedua-dua kemahiran tersebut pada tahap sederhana, kajian lanjutan perlu segera dilaksanakan untuk mencapai target Anjakan Kedua Pelan Pembangunan Pendidikan Malaysia PPPM (2013-2025) (Kementerian Pendidikan Malaysia, n.d.). Walaupun sudah enam tahun berada di sekolah rendah jenis kebangsaan, namun murid hanya menunjukkan kemahiran berbahasa Melayu pada tahap yang terhad. Mereka juga didapati kurang lancar membaca dan kurang berupaya dalam penulisan menggunakan bahasa Melayu. Hasil maklumat kajian lanjutan dapat digunakan oleh pihak yang terlibat dalam perancangan kurikulum kerana murid bukan penutur natif dari SJK akan

Pengajaran Bahasa Melayu dalam Kalangan Pelajar Asing: Analisis Pola Kesalahan Tatabahasa dalam Penulisan 
menyambung pelajaran ke Sekolah Menengah Kebangsaan (SMK) yang menggunakan bahasa Melayu sepenuhnya.

Proses pengujian kemahiran membaca dan menulis dalam bahasa Melayu boleh diteruskan di peringkat sekolah menengah. Instrumen UPBM_SR boleh digunakan dan diubah suai mengikut kesesuaian responden. Dasar pengujian kecekapan bahasa rasmi negara telah dirintis untuk kegunaan di sekolah rendah jenis kebangsaan boleh diperluas kepada populasi yang lebih menyeluruh untuk mendapatkan data yang lebih komprehensif. Murid bukan penutur natif perlu mengubah persepsi dan lebih bermotivasi terhadap penguasaan bahasa Melayu untuk meningkatkan pencapaian akademik kerana semakin tinggi tahap kemahiran membaca dan menulis dalam bahasa Melayu, semakin cemerlang pencapaian akademik yang akan diperoleh di SMK. Kelewatan kajian lanjutan dijalankan mengakibatkan murid bukan penutur natif berumur 14 tahun ke atas mengalami proses pembelajaran yang sukar terhadap penguasaan bahasa Melayu sebagai bahasa kedua.

\section{Rujukan}

Abdul Rasid Jamian. (2011). Permasalahan Kemahiran Membaca dan Menulis Bahasa Melayu Murid-murid Sekolah Rendah di Luar Bandar. Jurnal Pendidikan Bahasa Melayu (Malay Language Education Journal (MyLEJ).

Azizi Ahmad, \& Mohd Isha Awang. (2008). Pengukuran dan penilaian pendidikan. Kuala Lumpur, Malaysia: Dewan Bahasa dan Pustaka.

Chew F. P. (2016). Masalah pembelajaran Bahasa Melayu dalam kalangan murid Cina sekolah rendah. Jurnal Pendidikan Bahasa Melayu -JPBM (Malay Language Education Journal - MyLEL), 6(2), 10-22.

Fadzilah Abd Rahman, Zuraini Jusoh, \& Norazlina Mohd Kiram. (2016, Oktober 31November 1). Kesesuaian item kemahiran mendengar ujian kecekapan Bahasa Melayu (UKBMC). Paper presented at International Conference on Education and Regional Development 2016 (ICERD 2016), Bandung, Indonesia.

Juntos, H. (2002). Language testing option. California: Robert Wood Johnson Faoundation.

Kementerian Pendidikan Malaysia. (n.d.). Pelan Pembangunan Pendidikan Malaysia (PPPP) (Pendidikan Prasekolah hingga Lepas Menengah). Kuala Lumpur: Kementerian Pelajaran Malaysia.

Khairul Nizam Mohamed Zuki. (2017). Penerimaan bahasa Melayu dalam kalangan pelajar India. Tesis Doktor Falsafah. Fakulti Pengajian Pendidikan, Universiti Putra Malaysia.

Khadijah Rohani Mohd. Yunus (2001). Kebolehbacaan dalam buku teks. Bahan Kursus Penulisan Buku Teks Sekolah Menengah. Bahagian Buku Teks, Kementerian Pendidikan Malaysia dan Majlis Buku Kebangsaan Malaysia.

Krejcie, R.V. \& Morgan, D.W. (1970). Determining sampel size for Research Activities. Educational and Psychological Measurement, 30, 607-610.

Mahzan Arshad. (2016). Prinsip dan amalan dalam pengajaran literasi Bahasa Melayu. Kuala Lumpur, Malaysia: Dewan Bahasa dan Pustaka.

Pengajaran Bahasa Melayu dalam Kalangan Pelajar Asing: Analisis Pola Kesalahan Tatabahasa dalam Penulisan 
Nora'azian Nahar. (2018). Tahap profesiensi Bahasa Melayu dan hubungannya dengan status sosioekonomi, motivasi belajar dan pencapaian akademik dalam kalangan murid bukan penutur natif di sekolah jenis kebangsaan. (Tesis PhD). Universiti Putra Malaysia, Serdang, Selangor.

Noor Habsah Ali. (2018). Strategi pembelajaran kemahiran menulis Bahasa Melayu sebagai Bahasa Kedua dalam Kalangan Pelajar Melanau Daerah Daro. Jurnal Pendidikan Bahasa Melayu (Malay Language Education Journal (MyLEJ), 8(1), 33-41.

Noor Zila Md Yusuf. (2015). Bahasa antara dalam pembelajaran Bahasa Melayu sebagai bahasa kedua. (Tesis PhD). Universiti Putra Malaysia, Serdang, Selangor.

Norsimah Mat Awal, Nadrah Abu Bakar, \& Norhashimah Jalaluddin, (2012). Pembelajaran bahasa Melayu sebagai bahasa kedua: Pengungkapan idea dalam penulisan pelajar sekolah menengah di Malaysia. Jurnal Melayu, 9, 227-240.

Zulkifley Hamid. (2014). Faktor persekitaran sekolah dan etnik dalam perancangan dan pelaksanaan program pendidikan Bahasa Melayu di Malaysia. GEOGRAFIA Online TM Malaysian Jurnal of Society and Space, 10(5), 99-109. 